\title{
EFEITO DA CASCA DE MANDIOCA SOBRE A QUALIDADE DA CARNE E PARÂMETROS RUMINAIS DE OVINOS
}

\author{
EFFECT OFCASSAVA PEEL ON MEAT QUALITY \\ AND RUMINAL PARAMETERS OF SHEEP
}

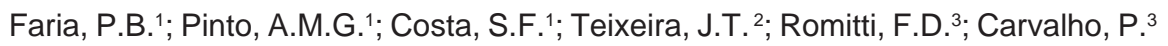 \\ e Silva, J.N. ${ }^{3}$
}

\begin{abstract}
'Universidade Federal de Lavras. Departamento de Medicina Veterinária. Lavras-MG. Brasil. peter@dmv.ufla.br

${ }^{2}$ Universidade Federal de Lavras. Departamento de Ciência dos Alimentos. Lavras-MG. Brasil.

${ }^{3}$ Instituto Federal de Educação. Ciência e Tecnologia de Mato Grosso. Santo Antonio do Leverger-MT. Brasil.
\end{abstract}

\section{PalaVRas ChaVe adicionaIS \\ Ácidos graxos. Subproduto.}

\section{RESUMO}

Objetivou-se com este trabalho, avaliar diferentes formas de processamento da casca de mandioca para uso na alimentação de ovinos e seus efeitos sobre a composição centesimal, qualidade de carne, perfil lipídico e morfometria ruminal. Para o experimento foram utilizados um total de 20 ovinos machos da raça Santa Inês desmamados com peso inicial 19,02 $\pm 0,21 \mathrm{~kg}$. O esquema fatorial utilizado foi um DIC (delineamento inteiramente casualizado), sendo 4 tratamentos (tratamento A: suplemento com casca de mandioca desidratada triturada em moinho com peneira de $12 \mathrm{~mm}$; tratamento B: suplemento com casca de mandioca desidratada triturada em moinho com peneira de $5 \mathrm{~mm}$; tratamento $\mathrm{C}$ : suplemento com casca de mandioca ensilada; tratamento $D$ : suplemento com casca de mandioca hidrolisada), cada animal foi considerado uma repetição, totalizando 5 repetições por tratamento. Os animais foram criados em sistema semiextensivo, em pastagem de Brachiaria decumbens e o fornecimento dos tratamentos na forma de suplemento na proporção de $1,5 \%$ do peso vivo (relação volumoso:concentrado de $62,5: 37,5 \%$ ), sendo a quantidade corrigida semanalmente em função do peso dos animais. $O$ experimento teve duração de 84 dias, incluindo o período de 14 dias de adaptação às dietas e os animais foram abatidos com peso final de $30,72 \pm 1,46 \mathrm{~kg}$, sendo coletado após abate e res-

\author{
Additional KEYWORDS \\ Byproducts. Fatty acids.
}

friamento ( 24 horas à $\pm 2^{\circ} \mathrm{C}$ ), amostras do músculo Longissimus lumborum para realização das análises físico-químicas e do perfil lipídico. Os resultados mostraram que não houve diferença significativa para as cinzas, umidade e proteína. Os animais que receberam suplemento com casca de mandioca hidrolisada apresentaram maiores valores de extrato etéreo. Não foi verificado modificação do perfil de ácidos graxos em virtude do processamento da casca de mandioca. A avaliação histológica revelou alteração no epitélio do rúmen e área da lâmina do omaso, com maiores valores no suplemento com uso da casca de mandioca moída grosseiramente. Para as variáveis da composição físico-químicas não foram verificadas influência dos suplementos. Os diferentes suplementos não foram suficientes para alterar os parâmetros de qualidade de carne, entretanto, a casca de mandioca hidrolisada ocasionou maior acúmulo de lipídeos no músculo.

\section{SUMMARY}

This work evaluated different forms of processing of cassava peel for use in sheep feeding and its effects upon composition, meat quality, lipid profile and rumen morphometrics. A total of 20 weaned Santa Inês male sheeps, with initial weight $19.02 \pm 0.21 \mathrm{~kg}$, were used. The fac- 
torial scheme utilized was a completely randomized design, with 4 treatments (A: supplement with dehydrated cassava peel ground, using a $12 \mathrm{~mm}$ sieve; B: supplement with dehydrated cassava peel ground using a $5 \mathrm{~mm}$ sieve; C: supplement with ensiled cassava peel; D: supplement with hydrolyzed cassava peel). Each animal was considered a replication, with 5 replications per treatment. The animals were reared in semiextensive system, on Brachiaria decumbens pasture. Treatments were supplied as supplement at proportion of $1.5 \%$ of live weight (ratio roughage: concentrate of $62.5: 37.5 \%$ ), amounts of food were adjusted, every week, according to the animals' weight. The experiment lasted 84 days, including 14 days for adaptation to the diets. Animals were slaughtered at $30.72 \pm 1.46 \mathrm{~kg}$ final weight; after slaughter and cooling (24 hours at

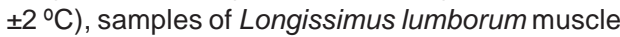
were collected to carry out the physicochemical analyses, and establish lipid profile. There were no significant differences for ashes, moisture and protein. The animals fed supplement with hydrolyzed cassava peel, presented higher values for ether extract. The fatty acid profile was not affected by processing type of cassava peels. The histological evaluation revealed alteration in the rumen epithelium and area of the omasal lamina, with higher values for coarsely ground cassava peel supplement. No influence of the supplements was found for physicochemical composition. The different supplements were not enough to alter the meat quality parameters, however, hydrolyzed cassava peel brought about increased accumulation of lipids in the muscle.

\section{INTRODUÇÃO}

A mandioca (Manihot esculenta, Crantz) destaca-se pela grande variedade de produtos e subprodutos, sendo que os resíduos gerados, como a casca de mandioca, farinha de varredura e massa de fecularia, podem ser utilizados como fonte alternativa na alimentação de ruminantes (Zeoula et al., 2003), contribuindo dessa forma para redução da perda deste material e diminuição dos custos na produção animal (Faria et al., 2011).

A casca de mandioca corresponde a um resíduo que apresenta como característica: baixa quantidade de proteína e grande quantidade de fibra e energia, sendo principalmente usada em animais para engorda em sistema intensivo ou extensivo, complementando a composição da pastagem (Abrahão et al., 2005).

Aspectos relacionados ao processamento e características do alimento podem interferir com o perfil lipídico da carne de ruminantes, com modificação da composição dos ácidos graxos da série $\omega 6$ e $\omega 3$ devido ao processo de biohidrogenação no rúmen (Nuernberg et al., 2008; Wood et al., 2008). Além disso, avaliação histológica dos componentes ruminais é uma técnica utilizada para verificar alterações nos processos morfofisiológicos em relação ao comportamento da mucosa e suas partes para diferentes alimentos, considerando modificações relacionadas a estrutura física, degradabilidade, digestibilidade e produção de ácidos graxos voláteis (Costa et al., 2008).

Apesar dos trabalhos avaliando o uso da casca de mandioca não terem mostrado influência sobre as características de carcaça e desempenho para ruminantes em diferentes sistemas de terminação (Lakpini et al., 1997; Faria et al., 2011; Abrahão et al., 2005), para ovinos, ainda não foram realizados estudos relacionados a qualidade de carne.

O objetivo deste trabalho foi avaliar diferentes formas de processamento da casca de mandioca (Manihot Sculenta, Crantz) sobre as características físico-químicas, composição centesimal, perfil de ácidos graxos do músculo Longissimus Lumborum e avaliação histológica dos compartimentos dos pré-estomagos.

\section{MATERIALE MÉTODOS}

O experimento foi conduzido na fazenda do IFMT-Campus São Vicente. Para o experimento foram utilizados 20 ovinos machos inteiros desmamados da raça Santa Inês, com idade aproximada de 90 dias e peso inicial de 19,02 $\pm 0,21 \mathrm{~kg}$. O esquema fatorial 


\section{CASCA DE MANDIOCA E QUALIDADE DA CARNE DE OVINOS}

utilizado foi um delineamento inteiramente casualizado (DIC, 4x5), sendo 4 tratamentos (SCMG: Suplemento com casca de mandioca desidratada triturada em moinho com peneira de $12 \mathrm{~mm}$; SCMF: suplemento com casca de mandioca desidratada triturada em moinho com peneira de $5 \mathrm{~mm}$; SCME: suplemento com casca de mandioca úmida triturada sem o uso de peneiras e ensilada e; SCMH: suplemento com casca de mandioca úmida triturada sem o uso de peneiras e hidrolisada com $0,5 \%$ de cal virgem (óxido de cálcio - $\mathrm{CaO}$ ).

Nos suplementos com casca de mandioca desidratada, estas foram picadas inicialmente com auxílio de um triturador sem peneiras, sendo depositadas para secar sobre uma lona em cima do piso em local coberto, até que a matéria seca fosse superior a $75 \%$. Posteriormente, esse material foi novamente passado no triturador com uso de peneiras com malha de $12 \mathrm{~mm}$ (rolão) e 5 $\mathrm{mm}$ (quirera), respectivamente. No suplemento com casca de mandioca úmida ensilada, as cascas de mandioca foram picadas e desidratadas até atingir em torno de 30 $\%$ de matéria seca e, em seguida, foram ensiladas por 30 dias em tambor de plástico (capacidade de 200 litros) para posterior uso. No suplemento com casca de mandioca úmida hidrolisada com óxido de cálcio, estas foram trituradas sem peneira e o processo de hidrólise realizado com uso da cal virgem $(\mathrm{CaO})$, colocada na proporção de $0,5 \% \mathrm{em}$ relação ao peso da matéria natural. Esse material hidrolisado foi desidratado até atingir em torno de $30 \%$ da matéria seca e armazenado em tambor plástico de 200 litros com tampa removível para uso durante duas semanas.

A casca de mandioca utilizada foi considerada o subproduto resultante da prélimpeza da raiz que chega a indústria, formado por cepa, ponta de raiz, casca e entrecasca.

Os animais foram criados em sistema semiextensivo, sendo pesados individualmente no início e semanalmente para ajuste da quantidade de suplemento a ser fornecido durante o período experimental. A área experimental foi composta de quatro piquetes com tamanho de 0,16 ha cada, formados exclusivamente por pastagem de Brachiaria decumbens com produção média estimada de $3216,49 \mathrm{~kg} / \mathrm{MS} / \mathrm{ha}$ (Costa et al., 2009). Os ovinos foram separados em grupos composto de 5 animais e cada grupo recebeu a dieta específica, fornecida no cocho duas vezes ao dia e sal mineral ad libitum em cocho próprio. O suplemento era misturado no momento do fornecimento e oferecido aos animais em quantidade ajustada semanalmente de acordo com o peso médio de cada grupo. Os animais eram manejados diariamente com uso de rodízio, ou seja, cada grupo permanecia apenas um dia em cada piquete e retornava ao inicial somente após o quarto dia. Esse manejo foi aplicado para reduzir possíveis variações decorrentes da ausência de uniformidade dos piquetes em termos de produção de forragem.

As dietas foram calculadas de acordo com as recomendações do NRC (1985), os tratamentos foram calculados para atender um fornecimento de $12 \%$ de proteina bruta (PB), com uma estimativa de consumo de 4,0\% MS por peso vivo (PV) e ganho diário de $150 \mathrm{~g}$ para cordeiros com $20 \mathrm{~kg}$ de PV, sendo os suplementos calculados com $21 \%$ PB e fornecidos na proporção de $1,5 \%$ do $\mathrm{PV}$, de forma a representar $37,5 \%$ da dieta total. Nas dietas experimentais, a inclusão de casca de mandioca ficou estabelecido em $45 \%$ do total da matéria seca para cada suplemento, sendo o peso deste ingrediente ajustado em função do valor de matéria seca determinado para casca de mandioca úmida e desidratada (tabela I).

O experimento teve duração de 84 dias, incluindo o período de 14 dias de adaptação às dietas, e os animais foram abatidos com peso final de $30,72 \pm 1,46 \mathrm{~kg}$. O abate foi realizado em condições humanitárias e de acordo com as boas práticas de fabricação. Em seguida, os animais foram conduzidos à câmara fria onde permaneceram num perío- 
FARIA, PINTO, COSTA, TEIXEIRA, ROMITTI, CARVALHO ESILVA

Tabela I. Composição(\%/MS) da casca de mandioca, Brachiaria decumbens e dos suplementos experimentais. (Composition (\%/DM) of cassava peel, Brachiaria decumbens and experimental supplements).

\begin{tabular}{lccccccc}
\hline Ingredientes & CMU & CMD & BD & SCMG & SCMF & SCME & SCMH \\
\hline Farelo de soja & - & - & - & 35,70 & 35,70 & 35,70 & 35,70 \\
Milho moído & - & - & - & 16,20 & 16,20 & 16,20 & 16,20 \\
Fosfato bicálcico & - & - & - & 2,00 & 2,00 & 2,00 & 2,00 \\
Premix & - & - & - & 0,40 & 0,40 & 0,40 & 0,40 \\
Sal & - & - & - & 0,20 & 0,20 & 0,20 & 0,20 \\
Uréia & - & - & - & 0,50 & 0,50 & 0,50 & 0,50 \\
Casca de mandioca & - & - & - & 45,00 & 45,00 & 45,00 & 45,00 \\
Composição química & & & & & & & \\
Matéria seca & 33,93 & 76,29 & 24,46 & 85,34 & 85,93 & 59,84 & 51,09 \\
Cinzas & 4,14 & 5,00 & 9,19 & 5,76 & 6,25 & 5,57 & 7,66 \\
Proteína bruta & 3,94 & 4,38 & 5,69 & 23,22 & 25,03 & 26,30 & 19,97 \\
Extrato etéreo & 0,90 & 0,39 & 0,84 & 0,81 & 0,53 & 0,66 & 0,65 \\
FDN & - & - & - & 23,8 & 21,1 & 21,8 & 16,7 \\
FDA & - & - & - & 11,5 & 12,5 & 10,3 & 12,1 \\
\hline
\end{tabular}

$\mathrm{CMU}=$ casca de mandioca umida; $\mathrm{CMD}=$ casca de mandioca desidratada; $\mathrm{BD}=$ Brachiaria decumbens; SCMG = suplemento com casca de mandioca desidratada triturada em moinho com peneira de $12 \mathrm{~mm}$; $\mathrm{SCMF}=$ suplemento com casca de mandioca desidratada triturada em moinho com peneira de $5 \mathrm{~mm}$; $\mathrm{SCME}=$ suplemento com casca de mandioca úmida ensilada; $\mathrm{SCMH}=$ suplemento com casca de mandioca úmida hidrolisada.

do de 24 h à temperatura de $\pm 2{ }^{\circ} \mathrm{C}$. Após esse período, realizou-se a coleta de amostras do músculo Longissimus lumborum para realização das análises físico químicas, centesimais e do perfil lipídico.

Os valores de $\mathrm{pH}$ final foram registrados no músculo Longissimus lumborum após o resfriamento das carcaças (24 h), com uso pHmetro Hanna Instruments.

Para realização da análise de cor, foi utilizado colorímetro MINOLTA CR 200b (Osaka-Japão), operando no sistema CIEL*a*b*, com iluminante D65. Na cor, ainda foram determinados os índices de saturação $\left(\mathrm{C}^{*}\right)$ e o ângulo de tonalidade (h*) (Ramos e Gomide, 2007).

Para a determinação da perda de peso por cocção (PPC), as amostras foram pesadas em balança semi-analítica, METTLER M P1210 (Toledo, Brasil), envolvidas em papel alumínio e submetidas a cozimento em chapa elétrica à $150^{\circ} \mathrm{C}$ até ultrapassar $72^{\circ} \mathrm{C}$.
Para determinação da maciez foi utilizada metodologia de Froning e Uijttenboogarte (1988), onde as amostras foram obtidas com amostrador cilíndrico de $1,27 \mathrm{~cm}$ de diâmetro e posteriormente seccionadas no sentido transversal das fibras musculares, utilizando uma sonda Warner Bratzler acoplada a um Texturômetro modelo TA XT-2.

As análises de umidade, proteína, extrato etéreo e cinzas foram realizadas em triplicatas e de acordo com Horwitz (1980).

Os lipídeos totais foram extraídos com clorofórmio-metanol, segundo o método de Folch et al. (1957) e separados e esterificados segundo conceitos estabelecidos por Hartman e Lago (1973). A análise dos ácidos graxos foi realizada em cromatógrafo Shimatzu CG 2010 (Agilent Technologies Inc., Palo Alto, CA, USA), equipado com detector de ionização de chama, injetor split na razão 1:50 e coluna capilar da Supelco $\mathrm{SP}^{\mathrm{TM}}-2560,100 \mathrm{mx} 0,25 \mathrm{~mm} \times 0,20 \mu \mathrm{m}$ (Supelco 


\section{CASCA DE MANDIOCA E QUALIDADE DA CARNE DE OVINOS}

Inc., Bellefonte, PA, USA). As condições cromatográficas foram temperatura inicial da coluna de $140^{\circ} \mathrm{C} / 5$ minutos; aumentada $4{ }^{\circ} \mathrm{C} /$ minuto até $240{ }^{\circ} \mathrm{C}$ e mantida por 30 minutos, totalizando 60 minutos. A temperatura do injetor foi $260{ }^{\circ} \mathrm{C}$ e a do detector $260^{\circ} \mathrm{C}$. O gás de arraste utilizado foi o hélio. Os ácidos graxos foram identificados por comparação aos tempos de retenção apresentados pelo padrão SupelcoTM37 standard FAME Mix (Supelco Inc., Bellefonte, PA, USA) e expressos em porcentagem do total de ácidos graxos identificados.

Foi estimada a atividade da enzima $\Delta^{9}$ dessaturase e elongase de acordo com MalauAduli et al. (1997) e Kazala et al. (1999).

$O$ índice de aterogenicidade e trombogenicidade, considerado como indicador de saúde relacionado ao risco de doença cardiovascular, foram determinados de acordo com Ulbricht e Southgate (1991).

Para a avaliação histológica das papilas, foram coletados fragmentos da parede do saco cranial do rúmen e fixados em formalina (10\%) por 24 horas e mantidos em álcool etílico a $70^{\circ} \mathrm{GL}$ até serem processados. Para a análise morfométrica das papilas ruminais e a determinação do índice mitótico (IM) das células da camada basal dos epitélios do rúmen, retículo e omaso, as lâminas foram coradas com Hematoxilina-Eosina (HE). A altura e a área das papilas ruminais foram mensuradas com o software KS300 contido em um analisador de imagens e para a determinação do IM, utilizou-se microscópio de luz em aumento de 400X. Foram contados todos os núcleos das células da camada basal do epitélio e todas as células com núcleo apresentando figuras mitóticas. $\mathrm{O}$ índice mitótico foi calculado dividindo-se o número de núcleos com figuras mitóticas pelo total de núcleos contados. O exame histológico constou de uma avaliação de todo corte histológico presente na lâmina de cada animal por tratamento nas diferentes regiões (Costa et al., 2008).

O delineamento utilizado no experimento foi inteiramente casualizado, consideran- do cada animal uma unidade experimental. Os dados obtidos foram submetidos à análise de variância utilizando o teste de Scott-Knott a $5 \%$ de significância com o programa computacional SISVAR $®$.

\section{RESULTADOSEDISCUSSÃO}

Os ovinos apresentaram um consumo médio de matéria seca para os suplementos, variando de 362,28 a 412,78 g/dia, apresentando uma taxa de substituição em relação a pastagem de Brachiaria decumbens de 36,42 a 41,19\% (tabela II), indicam que o fornecimento de nutrientes para os animais foi semelhante para todos os suplementos.

Os resultados da composição centesimal, mostraram que somente houve diferença para o teor de extrato etéreo no músculo Longissimus lumborum (lombo). Não sendo verificadas modificações dos demais parâmetros de composição centesimal e fisico-quimica analisados, independente do tratamento realizado para casca de mandioca nos suplementos (tabela III).

Os animais que receberam a dieta suplementada com casca de mandioca hidrolisada ( $\mathrm{SCMH})$ com óxido de cálcio $(\mathrm{CaO})$, apresentaram maiores valores de extrato etéreo $(\mathrm{p}<0,05)$. De acordo com Macedo et al. (2000), a gordura é o componente da carcaça que apresenta maior variação, sendo influenciada pelo sistema de terminação, pelo genótipo e pela razão idade/peso do animal. Madruga et al. (2005) avaliando diversas dietas para alimentação de cordeiros Santa Inês, verificaram resultado semelhante ao descrito nesse estudo, com diferenças observadas entre os tratamentos com relação ao teor de lipídeo na carne. Contudo, Macedo et al. (2008) não relataram efeito do sistema de alimentação sobre a composição centesimal da carne de cordeiros. Esse comportamento verificado para o SCMH, indica que o processo de hidrólise apresentou efeito positivo sobre a disponibilidade de nutrientes para os animais, uma vez que o consumo de matéria seca e taxa de substiuição ao con- 
FARIA, PINTO, COSTA, TEIXEIRA, ROMITTI, CARVALHO ESILVA

Tabela II. Fornecimento, consumo e taxa de substituição dos diferentes suplementos com casca de mandioca para ovinos em pastagem de Brachiaria decumbens. (Supply, consumption and rate of substitution of different supplements with cassava peel for sheep grazing Brachiaria decumbens).

\begin{tabular}{lcccc}
\hline Variáveis $(\mathrm{n}=5)$ & SCMG & SCMF & SCME & SCMH \\
\hline Consumo por grupo (kg/dia) & $2,162 \pm 0,102$ & $2,108 \pm 0,092$ & $3,449 \pm 0,146$ & $3,647 \pm 0,179$ \\
Fornecimento por animal (g/dia MS) & $369,01 \pm 17,41$ & $362,28 \pm 15,81$ & $412,78 \pm 17,47$ & $372,65 \pm 18,29$ \\
Taxa de substituição da pastagem ${ }^{1}$ & $37,75+1,78$ & $37,06+1,62$ & $42,22+1,76$ & $38,12+1,87$ \\
\hline
\end{tabular}

${ }^{1}$ Consumo estimado de $4 \%$ de matéria seca (MS) por peso vivo/animal/dia.

$\mathrm{SCMG}=$ suplemento com casca de mandioca desidratada triturada em moinho com peneira de $12 \mathrm{~mm}$; $\mathrm{SCMF}=$ suplemento com casca de mandioca desidratada triturada em moinho com peneira de $5 \mathrm{~mm}$; $\mathrm{SCME}=$ suplemento com casca de mandioca úmida ensilada; $\mathrm{SCMH}=$ suplemento com casca de mandioca úmida hidrolisada.

sumo de pastagem foi semelhante.

O aumento na deposição de lipídeos na carne encontrado no SCMH, estaria relacionado ao menor valor de FDN observado para este suplemento (tabela I), uma vez que essa fração é inversamente correlacionada ao consumo, influenciando a taxa de degradação, passagem pelo retículo-rúmen e ingestão de matéria seca total (Van Soest, 1994; Kozloski et al., 2006).

Em relação à qualidade de carne, não houve influência dos tratamentos sobre os parâmetros físico-químicos (tabela III). Rodrigues et al. (2008) verificaram comportamento semelhante com uso de diferentes níveis de polpa cítrica na alimentação de cordeiros, citando maiores valores de $\mathrm{L}^{*} \mathrm{e} \mathrm{a}^{*}$ e, semelhantes parab*. Madruga et al. (2005), avaliando diferentes dietas também não encontraram influência sobre os parâmetros de cor para a carne de cordeiros Santa Inês.

Neste trabalho não houve efeito dos suplementos sobre o ângulo de tonalidade $\left(h^{*}\right)$, que ficou entre $29,84 \mathrm{e} 31,82^{\circ} \mathrm{e}$, o índice de saturação $\left(C^{*}\right)$ de 14,54 à 15,02 , o que mostra de acordo com escala de cor no Sistema CieL*a*b*, uma tonalidade variando de vermelho para o laranja (Vermelho de 0 a $25^{\circ}$ e Laranja de 25 à $70^{\circ}$ ), porém com baixa intensidade. Por outro lado, Velasco et al . (2004) encontraram resposta semelhante para $C^{*}(16,75$ à 17,93$)$ porém com menores valores de $h^{*}(12,19$ a 18,20$)$. Essa diferença esta relacionada aos maiores valores de $\mathrm{b}^{*}$ e reduzido de $\mathrm{a}^{*}$ encontrados na carne dos animais deste estudo, uma vez que, Velasco et al. (2004) relatam média de 3,72 à 5,48 e de 16,24 à 17,44 , respectivamente para estes parâmetros.

O perfil lipídico da carne de cordeiro pode ser alterado em função do tipo de dieta e sistema de alimentação (Wood et al., 2008), contudo, neste experimento devido a composição e consumo semelhante dos suplementos em sistema de produção semi-extensivo, estes não promoveram alteração em relação ao composição dos ácidos graxos (AGs), tabela IV.

Os ácidos graxos em maior proporção encontrados foram: oleico (C18:1 $19 \mathrm{cis})$, palmítico (16:0), esteárico (C18:0), linoleico

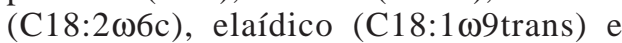
mirístico (C14:0). Estes resultados estão de acordo com os trabalhos de Bonagurio $\mathrm{Ga}$ llo et al. (2007) e Madruga et al. (2005).

De forma geral é verificado um aumento nos teores dos ácidos graxos poliinsaturados em relação aos saturados para animais criados em sistema de pastagem, sendo observado um aumento na quantidade de ácidos graxos da série $\omega$-3 em relação a $\omega 6$ (Rossato et al., 2010; Faria et al., 2012). 


\section{CASCA DE MANDIOCA E QUALIDADE DA CARNE DE OVINOS}

Tabela III. Características da carne de ovinos alimentados com suplementos com casca de mandioca. (Meat characteristics of sheep fed different supplements with cassava peel).

\begin{tabular}{lcccccc}
\hline Variáveis & SCMG & SCMF & SCME & SCMH & CV $(\%)$ & Valor p \\
\hline Luminosidade $\left(\mathrm{L}^{*}\right)$ & 38,61 & 38,67 & 39,21 & 37,94 & 4,60 & 0,7330 \\
Teor de vermelho $\left(\mathrm{a}^{*}\right)$ & 12,53 & 12,78 & 12,76 & 12,81 & 8,18 & 0,9718 \\
Teor de amarelo $\left(\mathrm{b}^{*}\right)$ & 7,35 & 7,29 & 7,86 & 7,43 & 10,71 & 0,6697 \\
Índice de saturação da cor $\left(\mathrm{C}^{*}\right)$ & 14,54 & 14,76 & 15,02 & 14,84 & 5,06 & 0,7860 \\
Ângulo de tonalidade da cor $\left(\mathrm{h}^{*}\right)$ & 30,43 & 29,84 & 31,82 & 30,10 & 13,83 & 0,8824 \\
Perda de peso por cozimento $(\%)$ & 30,39 & 29,10 & 30,57 & 29,51 & 12,05 & 0,9019 \\
pH final as 24 h & 5,67 & 5,64 & 5,64 & 5,64 & 0,58 & 0,3709 \\
Força de cisalhamento (kgf) & 3,17 & 3,28 & 3,56 & 3,67 & 15,57 & 0,4431 \\
Cinzas (\% MN) & 1,13 & 1,18 & 1,14 & 1,10 & 8,72 & 0,6598 \\
Umidade (\%) & 76,14 & 76,45 & 75,93 & 75,68 & 0,72 & 0,1763 \\
Extrato etéreo (\% MN) & $1,25^{\mathrm{b}}$ & $1,35^{\mathrm{b}}$ & $1,53^{\mathrm{b}}$ & $2,21^{\mathrm{a}}$ & 33,13 & 0,0437 \\
Proteína (\% MN) & 22,76 & 21,58 & 21,62 & 21,75 & 5,20 & 0,3412 \\
\hline
\end{tabular}

a,bMédias seguidas por letras minúsculas distintas na linha diferem pelo teste de Scott-Knott $(p<0,05)$. $\mathrm{SCMG}=$ suplemento com casca de mandioca desidratada triturada em peneira de $12 \mathrm{~mm}$; SCMF= suplemento com casca de mandioca desidratada triturada em peneira de $5 \mathrm{~mm}$; SCME $=$ suplemento com casca de mandioca úmida ensilada; $\mathrm{SCMH}=$ suplemento com casca de mandioca úmida hidrolisada; $\mathrm{CV}=$ coeficiente de variação; $\mathrm{MN}=$ matéria natural.

Neste trabalho, os animais foram criados em pastagem e receberam uma suplementação com as dietas, apresentando uma carne com perfil lipídico semelhante a de ovinos criados em sistema extensivo (Bonagurio Gallo et al., 2008; Faria et al., 2012; Nuernberg et al., 2008). Macedo et al. (2008), também não verificaram efeito da dieta no lombo de cordeiros sobre os valores dos ácidos graxos mirístico (C14:0), heptadecanóico (C17:1) e esteárico (C18:0).

Apesar dos maiores valores de lipídeos encontrados na carne dos animais com uso da casca de mandioca hidrolisada, o perfil lipídico foi semelhante entre os tratamentos, indicando que as características dos diferentes suplementos não foram suficientes para promover alteração nos parâmetros relacionados à composição dos ácidos graxos (tabela IV). Resultados semelhantes foram encontrados por Velasco et al. (2004) trabalhando com diferentes suplementos na terminação de cordeiros que encontraram somente efeito para os ácidos graxos C12:0, C18:1, C20:4 $\omega 6$ e total de monoinsaturados.
Estes resultados sugerem que o processo de hidrólise apesar de melhorar a disponibilidade de nutrientes, o fator determinante da composição lipídica estaria relacionado a maiores quantidades de ácidos graxos $\omega 3$ encontrados na pastagem (Wood et al., 2008). Efeitos sobre o perfil de ácidos graxos da carne de cordeiro foram observados nos trabalhos com inclusão de ingredientes ricos em lipídeos como caroço de algodão e semente de girassol (Macedo et al., 2008; Madruga et al., 2008).

Considerando as recomendações nutricionais da Organização Mundial da Saúde (World Health Organization, 2003) em que a relação entre ácidos graxos poliinsaturados e saturados (P/S) deve ser superior a 0,4 ; verifica-se neste trabalho que nos diferentes tratamentos, a carne ovina apresentou valores inferiores a este índice $(0,17$ a 0,20$)$, tabela IV. Resultados inferiores foram relatados por Madruga et al. (2005), que encontraram para relação $(\mathrm{P} / \mathrm{S})$ médias de 0,05 a 0,10 e proporção de ácidos graxos poliinsaturados de 2,25 a 5,01\%. Contudo, 
FARIA, PINTO, COSTA, TEIXEIRA, ROMITTI, CARVALHO ESILVA

Tabela IV. Perfil lipídico da carne de ovinos alimentados com diferentes suplementos com casca de mandioca. (Lipid profile of sheep meat fed different supplements with cassava peel).

\begin{tabular}{|c|c|c|c|c|c|c|}
\hline $\begin{array}{c}\text { Ácidos graxos } \\
\text { (\% composição lipídica) }\end{array}$ & SCMG & SCMF & SCME & $\mathrm{SCMH}$ & CV (\%) & Valor $p$ \\
\hline C12:0 & 0,14 & 0,27 & 0,26 & 0,36 & 88,21 & 0,5307 \\
\hline C14:0 & 2,08 & 2,41 & 2,08 & 2,65 & 19,43 & 0,1671 \\
\hline C14:1 & 0,15 & 0,11 & 0,06 & 0,09 & 101,12 & 0,5117 \\
\hline C15:0 & 0,40 & 0,33 & 0,27 & 0,43 & 55,56 & 0,5989 \\
\hline C16:0 & 22,93 & 23,80 & 23,45 & 22,99 & 3,86 & 0,4013 \\
\hline C16:1 & 1,44 & 1,31 & 1,37 & 1,36 & 18,43 & 0,8806 \\
\hline C17:0 & 1,04 & 1,11 & 0,90 & 1,10 & 37,70 & 0,8304 \\
\hline C17:1 & 0,45 & 0,22 & 0,38 & 0,77 & 89,54 & 0,2242 \\
\hline C18:0 & 21,59 & 22,08 & 21,53 & 20,69 & 10,78 & 0,8170 \\
\hline C18:1 $\omega 9$ trans & 2,24 & 1,58 & 1,63 & 1,86 & 33,02 & 0,3238 \\
\hline $\mathrm{C} 18: 1 \omega 9$ cis & 37,23 & 37,28 & 38,94 & 37,71 & 7,41 & 0,7524 \\
\hline $\mathrm{C} 18: 2 \omega 6$ cis & 5,95 & 6,10 & 5,19 & 5,84 & 27,70 & 0,8145 \\
\hline C20:0 & 0,19 & 0,24 & 0,10 & 0,14 & 45,26 & 0,0856 \\
\hline 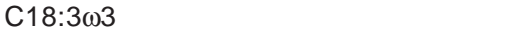 & 0,79 & 0,52 & 0,51 & 0,50 & 35,62 & 0,1154 \\
\hline C21:0 & 0,60 & 0,30 & 0,70 & 0,63 & 41,46 & 0,0642 \\
\hline C20:2 & 0,33 & 0,46 & 0,04 & 0,57 & 183,91 & 0,6127 \\
\hline $\mathrm{C} 20: 3 \omega 6$ & 0,15 & 0,14 & 0,10 & 0,07 & 76,33 & 0,4373 \\
\hline 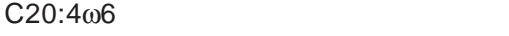 & 1,57 & 1,25 & 2,21 & 1,79 & 38,44 & 0,1749 \\
\hline C22:2 & 0,56 & 0,27 & 0,05 & 0,34 & 211,67 & 0,6720 \\
\hline $\mathrm{C} 20: 5 \omega 3$ & 0,14 & 0,14 & 0,18 & 0,06 & 94,01 & 0,4507 \\
\hline $\mathrm{C} 22: 6 \omega 3$ & 0,03 & 0,10 & 0,06 & 0,07 & 69,85 & 0,1644 \\
\hline Total ácidos graxos saturados & 48,97 & 50,53 & 49,29 & 48,99 & 5,11 & 0,7363 \\
\hline Total ácidos graxos monoinsaturados & 41,52 & 40,50 & 42,37 & 41,79 & 6,70 & 0,7589 \\
\hline Total ácidos graxos poliinsaturados & 9,51 & 8,97 & 8,33 & 9,23 & 22,81 & 0,8265 \\
\hline Total ácidos graxos da série $\omega 3$ & 0,96 & 0,76 & 0,75 & 0,63 & 32,57 & 0,2652 \\
\hline Total ácidos graxos da série $\omega 6$ & 7,67 & 7,49 & 7,49 & 7,69 & 20,85 & 0,9948 \\
\hline Relação do total de $\omega 6 / \omega 3$ & 8,33 & 10,75 & 11,16 & 13,19 & 36,33 & 0,3166 \\
\hline Relação total poliinsaturados/saturados & s 0,20 & 0,18 & 0,17 & 0,19 & 25,29 & 0,8236 \\
\hline Atividade da $\Delta 9$-desaturase ${ }^{\mathrm{C} 16}$ & 5,91 & 5,20 & 5,50 & 5,60 & 18,62 & 0,7609 \\
\hline Atividade da $\Delta 9$-desaturase ${ }^{\mathrm{C} 18}$ & 63,32 & 62,73 & 64,44 & 64,50 & 6,22 & 0,8678 \\
\hline Atividade da elongase ${ }^{\mathrm{C} 16-\mathrm{C} 18}$ & 44,76 & 44,09 & 45,66 & 45,52 & 6,02 & 0,7818 \\
\hline Atividade da thioesterase ${ }^{\mathrm{C} 16-14}$ & 91,65 & 90,81 & 91,85 & 89,67 & 1,94 & 0,2313 \\
\hline Índice de aterogenicidade & 0,54 & 0,57 & 0,56 & 0,58 & 7,04 & 0,3721 \\
\hline Índice de trombogenicidade & 1,70 & 1,84 & 1,74 & 1,74 & 9,91 & 0,6375 \\
\hline
\end{tabular}

SCMG = suplemento com casca de mandioca desidratada triturada em moinho com peneira de $12 \mathrm{~mm}$; $\mathrm{SCMF}=$ suplemento com casca de mandioca desidratada triturada em moinho com peneira de $5 \mathrm{~mm}$; $\mathrm{SCME}=$ suplemento com casca de mandioca úmida ensilada; $\mathrm{SCMH}=$ suplemento com casca de mandioca úmida hidrolisada; CV= coeficiente de variação.

Madruga et al. (2008) citam média de 0,21 a 0,26 para relação $\mathrm{P} / \mathrm{S}$, com maior proporção de ácidos graxos poliinsaturados $(10,40 \mathrm{a}$ $13,54 \%)$ e menores valores de ácidos graxos monoinsaturados $(35,86$ a 40,82\%).
Para a dieta humana é desejável que seja mantida uma proporção de consumo de $4: 1$ em relação aos ácidos graxos $\omega 6 / \omega 3$ (World Health Organization, 2003). Entretanto, na carne dos animais desse estudo, os resulta- 


\section{CASCA DE MANDIOCA E QUALIDADE DA CARNE DE OVINOS}

dos mostraram valores médios de relação $\omega 6 / \omega 3$ de 8,33 a 13,19 , o que representa de 2 a 3 vezes o recomendado, constituindo fator de risco para desenvolvimento de certos tipos de câncer e doenças cardíacas se considerado somente o seu consumo.

Os índices de aterogenicidade e trombogenicidade, encontrados neste trabalho são semelhantes aos obtidos por Arruda et al. (2012) para cordeiros $(0,64$ e 1,37 , respectivamente). Estes índices estão relacionados às quantidades de ácidos graxos saturados, poliinsaturados e da série $\omega 6$, sendo um indicador de saúde associado ao risco de doença cardiovascular (Ulbritch e Southgate, 1991). Dessa forma, quanto menor for os índices de aterogenicidade e trombogenicidade de determinado produto, melhor será para a saúde o seu consumo.

Considerando os diferentes suplementos, verifica-se que ocorreram alterações no rúmen em relação à área do epitélio e do epitélio total (queratina + epitélio) e no omaso para área da lâmina (tabela V).

Tabela $\boldsymbol{V}$. Morfometria ruminal de ovinos alimentados com diferentes suplementos com casca de mandioca. (Morphometrics rumen of sheep fed different supplements with cassava peel).

\begin{tabular}{|c|c|c|c|c|c|c|}
\hline Variáveis & SCMG & SCMF & SCME & $\mathrm{SCMH}$ & CV (\%) & Valor $p$ \\
\hline \multicolumn{7}{|l|}{ Rumen } \\
\hline Epitélio $\left(\mu m^{2}\right)$ & $0,43^{\mathbf{a}}$ & $0,32^{b}$ & $0,41^{\mathrm{a}}$ & $0,31^{\mathrm{b}}$ & 17,75 & 0,0150 \\
\hline Queratina $\left(\mu \mathrm{m}^{2}\right)$ & 0,05 & 0,05 & 0,05 & 0,04 & 29,18 & 0,2619 \\
\hline Epitélio total & $0,48^{a}$ & $0,36^{b}$ & $0,46^{a}$ & $0,35^{b}$ & 17,79 & 0,0189 \\
\hline Índice mitótico & 0,01 & 0,01 & 0,02 & 0,01 & 34,62 & 0,2003 \\
\hline Índice mitótico (\%) & 1,39 & 1,11 & 1,57 & 1,04 & 35,30 & 0,2486 \\
\hline Área papila $\left(\mu \mathrm{m}^{2}\right)$ & 2,49 & 1,15 & 1,56 & 1,64 & 51,88 & 0,1531 \\
\hline Altura papila $(\mu \mathrm{m})$ & 3,60 & 2,73 & 3,72 & 2,94 & 26,93 & 0,2396 \\
\hline \multicolumn{7}{|l|}{ Reticulo } \\
\hline Epitélio $\left(\mu m^{2}\right)$ & 0,46 & 0,46 & 0,48 & 0,49 & 14,40 & 0,8163 \\
\hline Queratina $\left(\mu \mathrm{m}^{2}\right)$ & 0,09 & 0,08 & 0,09 & 0,08 & 23,64 & 0,7295 \\
\hline Epitélio total & 0,55 & 0,54 & 0,57 & 0,57 & 13,54 & 0,8837 \\
\hline Índice mitótico & 0,02 & 0,02 & 0,02 & 0,02 & 29,76 & 0,1384 \\
\hline Índice mitótico \% & 1,81 & 2,09 & 1,59 & 2,47 & 30,11 & 0,1533 \\
\hline Área prega $\left(\mu m^{2}\right)$ & 0,18 & 0,34 & 0,24 & 0,21 & 79,64 & 0,5721 \\
\hline Altura prega $(\mu \mathrm{m})$ & 0,69 & 0,79 & 0,89 & 0,80 & 22,01 & 0,3734 \\
\hline \multicolumn{7}{|l|}{ Omaso } \\
\hline Epitélio $\left(\mu \mathrm{m}^{2}\right)$ & 0,39 & 0,38 & 0,37 & 0,41 & 19,78 & 0,7816 \\
\hline Queratina $\left(\mu \mathrm{m}^{2}\right)$ & 0,06 & 0,05 & 0,06 & 0,05 & 24,19 & 0,1991 \\
\hline Epitélio total & 0,45 & 0,43 & 0,43 & 0,46 & 19,18 & 0,8788 \\
\hline Índice mitótico & 0,01 & 0,01 & 0,01 & 0,01 & 27,49 & 0,6218 \\
\hline Índice mitótico (\%) & 1,16 & 1,07 & 0,96 & 0,99 & 27,15 & 0,6900 \\
\hline Altura lâmina ( $\mu \mathrm{m})$ & 4,37 & 2,78 & 3,23 & 2,47 & 32,34 & 0,0516 \\
\hline Área lâmina $\left(\mu m^{2}\right)$ & $2,72^{\mathrm{a}}$ & $1,55^{\mathrm{b}}$ & $1,72^{\mathrm{b}}$ & $1,38^{b}$ & 38,45 & 0,0370 \\
\hline Altura papila $(\mu \mathrm{m})$ & 0,33 & 0,26 & 0,25 & 0,25 & 18,81 & 0,0687 \\
\hline Área papila $\left(\mu \mathrm{m}^{2}\right)$ & 0,12 & 0,08 & 0,07 & 0,08 & 43,42 & 0,2406 \\
\hline
\end{tabular}

a,bMédias seguidas por letras minúsculas distintas na linha diferem pelo teste de Scott-Knott $(p<0,05)$. $\mathrm{SCMG}=$ suplemento com casca de mandioca desidratada triturada em moinho com peneira de $12 \mathrm{~mm}$; $\mathrm{SCMF}=$ suplemento com casca de mandioca desidratada triturada em moinho com peneira de $5 \mathrm{~mm}$; $\mathrm{SCME}=$ suplemento ação com casca de mandioca úmida ensilada; $\mathrm{SCMH}=$ suplemento com casca de mandioca úmida hidrolisada; $\mathrm{CV}=$ coeficiente de variação. 
Apesar de não se verificar efeito sobre os valores de altura de papilas no rúmen, as dietas com maior tamanho de partícula (SCMG e SCME), ocasionaram aumento da área do epitélio e epitélio total. $\mathrm{O}$ aumento do epitélio é citado como reflexo da maior produção e absorção dos ácidos graxos voláteis (AGVs) (Costa et al., 2008). Apesar de não ter sido avaliado a produção de AGVs, o resultado encontrado neste estudo, estaria relacionado principalmente a forma física da casca de mandioca desses suplementos, pois segundo Beharka et al. (1998) e Coverdale et al. (2004) em bezerros, o uso de dietas com partículas grosseiras promoveu maior desenvolvimento do epitélio ruminal com maiores concentrações de propionato e butirato.

Não foi verificado modificação dos demais parâmetros avaliados no rúmen e retículo, com os suplementos com casca de mandioca. Wang et al. (2009) também não verificaram efeito sobre a largura e densidade das papilas do saco ventral e dorsal do rúmen, avaliando diferentes níveis de amido na dieta. Segundo Neto et al. (2000), é verificado uma maior fermentação ruminal quando os animais são alimentados com rações que contenham como fonte energética a mandioca em comparação ao milho, devido a maior quantidade de amilopectina e baixa quantidade de proteína neste alimento, favorecendo degradação ruminal pelos microrganismos (Moron et al., 2000).

O suplemento SCMG, promoveu no omaso aumento na área da lamina, o que segundo Medeiros et al. (2008), esta rela-

\section{BIBLIOGRAFIA}

Abrahão, J.J.S.; Prado, I.N.; Perotto, D. e Moletta, J.L. 2005. Características de carcaças e da carne de tourinhos submetidos a dietas com diferentes níveis de substituição do milho por resíduo umido da extração da fécula de mandioca. Rev Bras Zootecn, 34: 1640-1650.

Arruda,P.C.L.; Pereira, E.S.; Pimentel, P.G.;Bomfim, M.A.D.; Mizubuti, I.Y.; Ribeiro, E.L.A.; Fontenele, cionado a maior retenção do alimento no rúmen-reticuloe, animais com maiores níveis de concentrado na dieta tendem apresentar redução no tamanho desse órgão, devido ao maior fluxo da dieta.

Os diferentes processamentos da casca de mandioca promoveram modificação de alguns aspectos histológicos dos componentes digestivos o que pode estar relacionado à diferença na produção de ácidos graxos voláteis, principalmente pelos ácidos butírico e propiônico, que são utilizados como fonte de energia para crescimento do tecido epitelial e produção de glicose através de gluconeogênese (Costa et al., 2008). A maior quantidade de gordura intramuscular verificada para o suplemento com casca de mandioca com uso da técnica de hidrólise, pode estar relacionado a maior produção de butirato, que é um dos principais precursores para síntese de gordura em ruminantes.

\section{CONCLUSÃO}

Os diferentes processamentos da casca de mandioca fornecidos na forma de suplementos, não influenciaram os parâmetros de qualidade e perfil de ácidos graxos da carne dos ovinos, entretanto, com o uso da casca de mandioca hidrolisada ocorreu aumento na deposição de lipídeos no músculo. A forma física dos suplementos promovera alteração da morfometria ruminal com aumento do epitelio ruminal e área da lâmina do omaso com uso da casca de mandioca desidratada moída grosseiramente. 


\section{CASCA DE MANDIOCA E QUALIDADE DA CARNE DE OVINOS}

ment of the rumen of neonatal calves. $J$ Dairy Sci, 81: 1946-1955.

Bonagurio Gallo, S.; Siqueira, E.R. e Rosa, G.T. 2007. Efeito da nutrição da ovelha e do cordeiro sobre o perfil de ácidos graxos do músculo Triceps brachii de cordeiros. Rev Bras Zootecn, 36: 2069-2073.

Costa, B.M.; Ledo, C.A.S.; Silva, M.C. e Teixeira, V.I. 2009. Estimativa da produção de forragem em pastagem de Brachiaria decumbens. Arch Zootec, 58: 141-144.

Costa, S.F.; Pereira, M.N.; Melo, L.Q.; Resende Júnior, J.C. e Chaves, M.L. 2008. Alterações morfológicas induzidas por butirato, propionato e lactato sobre a mucosa ruminal e a epiderme de bezerros - I Aspectos histológicos. Arq Bras Med Vet Zoo, 60: 1-9.

Coverdale, J.A.; Tyler, H.D.; Quigley, J.D. and Brumm, J. 2004. Effect of various levels of forage and form of diet on rumen development and growth in calves. J Dairy Sci, 87: 25542562.

Faria, P.B.; Silva, J.N.; Rodrigues, A.Q.; Teixeira, P.D.; Melo, L.Q.; Costa, S.F.; Rocha, M.F.M. e Pereira, A.A. 2011. Processamento da casca de mandioca na alimentação de ovinos: desempenho, características de carcaça, morfologia ruminal e eficiência econômica. Rev Bras Zootec, 40: 2929-2937.

Faria, P.B.; Bressan, M.C.; Vieira, J.O.; VicenteNeto, J.; Ferrão, S.P.; Rosa, F.C.; Monteiro, E.M.; Cardoso, M.G. and Gama, L.T. 2012. Meat quality and lipid profiles in crossbred lambs finished on clover-rich pastures. Meat Sci, 90: 733-738.

Folch, J.; Lees, M. and Stanley, S.A. 1957. A simple method for isolation and purification of total lipids from animal tissues. J Biol Chem, 226: 479-503.

Froning, G.W. and Uijttenboogaart, T.G. 1988. Effect of post mortem electrical stimulation on color, texture, $\mathrm{pH}$ and cooking loses of hot and cold deboned chicken broiler breast meat. Poultry Sci, 67: 1536-1544.

Hartman, L. and Lago, R.C.A. 1973. Rapid preparation to fatty acids methyl esters from lipids. Lab Pract, 22: 475-476.

Horwitz, W. 1980. Official methods of analysis of Association of Official Analytical Chemists. 13 ed. AOAC. Whashington. $1018 \mathrm{pp}$.

Kazala, E.C.; Lozeman, F.J.; Mir, P.S.; Laroche, A.;
Bailey, D.R. and Weselake, R.J.. 1999. Relationship of fatty acid composition to intramuscular fat content in beef from crossbred Wagyu cattle. J Anim Sci, 77: 1717-1725.

Kozloski, G.V.; Trevisan, L.M.; Bonnecarrére, C.J.; Härter, C.J.; Fiorentini, G.; Galvani, D.B. e Pires, C.C. 2006. Níveis de fibra em detergente neutro na dieta de cordeiros: consumo, digestibilidade e fermentação ruminal. Arq Bras Med Vet Zoo, 58: 893-900.

Lakpini, C.A.M.; Balogun, B.I. and Alawa, J.P. 1997. Effects of graded levels of sun-dried cassava peels in supplement diets fed to Red Sokoto goats in first trimester of pregnancy. Anim Feed Sci Tech, 67: 197-204.

Macedo, F.A.F.; Siqueira, E.R.; Martins, E.N. e Macedo, R.M.G. 2000. Qualidade de carcaças de cordeiros Corriedale, Bergamácia x Corriedale e Hampshire Down $\times$ Corriedale, terminados em pastagem e confinamento. Rev Bras Zootecn, 29: 1520-1527.

Macedo, V.P.; Garcia, C.A.; Silveira, A.C.; Monteiro, A.L.G.; Macedo, F.A.F. e Spers, R.C. 2008. Composições tecidual e química do lombo de cordeiros alimentados com rações contendo semente de girassol em comedouros privativos. Rev Bras Zootecn, 37: 1860-1868.

Madruga, M.S.; Sousa, W.H.; Rosales, M.D.; Cunha, M.G.G. e Ramos, J.L.F. 2005. Qualidade da carne de cordeiros Santa Inês terminados com diferentes dietas. Rev Bras Zootecn, 34: 309315.

Madruga, M.S.; Vieira, T.R.L.; Cunha, M.G.G.; Pereira Filho, J.M.; Queiroga, R.C.R.E. e Sousa, W.H. 2008. Efeito de dietas com níveis crescentes de caroço de algodão integral sobre a composição química e o perfil de ácidos graxos da carne de cordeiros Santa Inês. Rev Bras Zootecn, 37: 1496-1502.

Malau-Aduli, A.E.O.; Siebert, B.D.; Bottema, C.D.K. and Pitchford, W.S. 1997. A comparison of the fatty acid composition of triacylglycerols in adipose tissue from Limousin and Jersey cattle. Aust J Agr Resour Ec, 48: 715-722.

Medeiros, G.R.; Carvalho, F.F.R.; Ferreira, M.A.; Dutra Júnior, W.M.; Santos, G.R.A. e Andrade, D.K.B. 2008. Efeito dos níveis de concentrado sobre os componentes não-carcaça de ovinos Morada Nova em confinamento. Rev Bras Zootecn, 37: 1063-1071. 


\section{FARIA, PINTO, COSTA, TEIXEIRA, ROMITTI, CARVALHO E SILVA}

Moron, I.R.; Teixeira, J.C.; Oliveira, A.I.G.; Perez, J.R.O. e Oliveira, J.S.E. 2000. Cinética da digestão ruminal do amido dos grãos de milho e sorgo submetidos a diferentes formas de processamento. Cienc Agrotec, 24: 208-212.

NRC. 1985. National Research Council. Nutrient requirements of sheep. $5^{\text {th }}$ ed. National Academy Press. Washington, D.C. 99 pp.

Neto, S.F.C.; Zeoula, L.M.; Branco, A.F.; Prado, I.N.; Santos, G.T.; Fregadolli, F.L.; Kassies, M.P. e Dalponte, A.O. 2000. Mandioca e resíduos das farinheiras na alimentação de ruminantes: digestibilidade total e parcial. Rev Bras Zootecn, 29: 2099-2108.

Nuernberg, K.; Fischer, A.; Nuernberg, G.; Ender, K. and Dannenberger, D. 2008. Meat quality and fatty acid composition of lipids in muscle and fatty tissue of Skudde lambs fed grass versus concentrate. Small Ruminant Res, 74: 279-283.

Ramos, E.M. e Gomide, L.A.M. 2007. Avaliação da qualidade de carnes: fundamentos e metodologias. Ed. UFV. Viçosa, MG. 599 pp.

Rodrigues, G.H.; Susin, I.; Pires, A.V.; Mendes, C.Q.; Urano, F.S. e Castillo, C.J.C. 2008. Polpa cítrica em rações para cordeiros em confinamento: características da carcaça e qualidade da carne. Rev Bras Zootecn, 37: 1869-1875.

Rossato, L.V.; Bressan, M.C.; Rodrigues, E.C.; Gama, L.T.; Bessa, R.J.B. e Alves, S.P.A. 2010. Parâmetros físico-químicos e perfil de ácidos graxos da carne de bovinos Angus e Nelore terminados em pastagem. Rev Bras Zootecn,
39: 1127-1134.

Ulbricht, T.L.V. and Southgate, D.A.T. 1991. Coronary heart disease:seven dietary factors. Lancet, 338: 985-992.

Van Soest, P.J. 1994. Nutritional ecology of the ruminant. $2^{\text {nd }}$ ed. Cornell University Press. New York. $476 \mathrm{pp}$.

Velasco, S.; Cañeque, V.; Lauzurica, S.; Pérez, C. and Huidobro, F. 2004. Effect of different feeds on meat quality and fatty acid composition of lambs fattened at pasture. Meat Sci, 66: 457465.

Wang, Y.H.; Xu, M.;Wang, F.N.;Yu, Z.P.;Yao, J.H.; Zan, L.S. and Yang, F.X. 2009. Effect of dietary starch on rumen and small intestine morphology and digesta $\mathrm{pH}$ in goats. Livest Sci, 122: 48-52.

Wood, J.D.; Enser, M.; Fischer, A.V.; Nute, G.R.; Sheard, P.R.; Richardson, R.I.; Hughes, S.I. and Whittington, F.M. 2008. Fat deposition, fatty acid composition and meat quality: A review. Meat Sci, 78: 343-358.

World Health Organization. 2003. Diet, nutrition and the prevention of chronic diseases. WHO Technical Report Series. Geneva, n. 916.

Zeoula, L.M.; Caldas Neto, S.F.; Geron, L.J.V.; Maeda, E.M.; Prado, I.N.; Dian, P.H.M.; Jorge, J.R.V. e Marques, J.A. 2003. Substituição do milho pela farinha de varredura de mandioca (Manihot esculenta Crantz) em rações de ovinos: consumo, digestibilidade, balanços de nitrogênio e energia e parâmetros ruminais. Rev Bras Zootecn, 32: 491-502. 